\title{
JNPH
}

Volume 5 No. 1 (Juli 2017)

(C) The Author(s) 2017

\section{FAKTOR-FAKTOR YANG BERHUBUNGAN DENGAN PERILAKU PENCEGAHAN KECELAKAAN PADA BALITA (ANTICIPATORY GUIDANCE) DI WILAYAH KERJA PUSKESMAS BASUKI RAHMAD KOTA BENGKULU TAHUN 2016}

\author{
FACTORS ASSOCIATED WITH BEHAVIORAL ACCIDENT PREVENTION IN \\ TODDLERS (ANTICIPATORY GUIDANCE) IN BASUKI \\ RAHMAT PUBLIC HEALTH CENTER IN BENGKULU CITY IN 2016
}

\author{
SUDIYANTO, TARMIZI DAUD, EPINA FELIZITA \\ SEKOLAH TINGGI ILMU KESEHATAN DEHASEN BENGKULU
}

\begin{abstract}
ABSTRAK
Kecelakaan menjadi masalah kesehatan masyarakat di negara berkembang dan merupakan penyebab utama kematian diperkirakan setiap tahunnya di Indonesia hampir 1 juta anak meninggal dalam kecelakaan. Tujuan penelitian ini untuk mengetahui faktor-faktor yang terkait dengan perilaku pencegahan kecelakaan pada balita (antisipatif bimbing) di Puskesmas Basuki Rahmat Kota Bengkulu pada tahun 2016. Metode penelitian ini menggunakan desain deskriptif analitik, dengan menggunakan rancangan cross-sectional. Populasi dalam penelitian ini adalah semua ibu dengan balita di Puskesmas Basuki Rahmat pada tahun 2014 sebanyak 1097 orang dengan sampel sebanyak 92 responden yang diambil dengan teknik accidental sampling. Analisis data menggunakan Chi square pada tabel distribusi frekuensi dan bivariat. Hasil penelitian ini menunjukkan bahwa hampir sebagian besar responden $(40,2 \%)$ memilliki sikap tidak baik terhadap pencegahan kecelakaan pada bayi, sebagian besar responden $(26,1 \%)$ memiliki pendidikan dasar, sebagian kecil responden $(25,0 \%)$, kurang pengetahuan, hampir setengah responden $(37,0 \%)$, memiliki sikap kurang baik, ada hubungan tentang pendidikan, pengetahuan dan perilaku ibu dengan pencegahan kecelakaan pada bayi di Puskesmas Basuki Rahmat Kota Bengkulu 2016. Pencegahan dapat dilakukan dengan cara meningkatkan sosialisasi tentang sarana dan pencegahan kecelakaan pada bayi ke masyarakat, terutama pada wanita yang memiliki balita.
\end{abstract}

Kata kunci: pendidikan, pengetahuan, sikap, perilaku pencegahan kecelakaan kerja

\begin{abstract}
Accidents become public health problems in developing countries and is a major cause of death was estimated that each year in Indonesia every year nearly 1 million children died in an accident.The purpose of this study to determine Factors Associated With Behavioral Accident Prevention In Toddlers (anticipatory Guidance) in Puskesmas Basuki Rahmat Bengkulu City in 2016. This research method using descriptive analytic desian, using cross-sectional design. The population in this study is the population in this study are all mothers with children under five in Puskesmas Basuki Rahmat in 2014 as many as 1097 people with a sample of 92 respondents taken by accidental sampling technique, on analysis by univariate using frequency distribution tables and bivariate using Chi square. The results of this study show that almost the majority of
\end{abstract}


respondents $(40.2 \%)$ have unfavorable attitude toward accident prevention in infants, a small majority of respondents $(26.1 \%)$, have a basic education, a small portion of the respondents $(25$, $0 \%$ ), have a lack of knowledge, almost half of respondents (37.0\%), have unfavorable attitudes, There is a relationship education, knowledge and mother attitude with the behavior of accident prevention in infants in Puskesmas Basuki Rahmat Bengkulu City 2016. The accident of prevention in infants to the community, especially in women who have a toddler

Keywords: education, knowledge, attitude, behavior accident prevention

\section{PENDAHULUAN}

Anak merupakan karunia tuhan yang harus di syukuri, dimana seseorang yang sudah berkeluarga sangat berharap mempunyai anak, jika anak dalam keadaan sehat, orang tuapun senang, bangga dan bahagia. Pertumbuhan mempunyai dampak terhadap aspek fisik, sedangkan perkembangan adalah segala perubahan yang terjadi pada anak baik secara fisik, kognitif, emosi maupun psikososial (Soetjiningsih, 2005).

Pada masa perkembangan anak, hal-hal baru yang anak temukan pada saat bermain bisa menjadi sesuatu yang berbahaya pada anak yang dapat menyebabkan kecelakaan baik disengaja maupun tidak. Kecelakaan dan cedera pada anak dapat terjadi dimana saja. Setiap saat bahaya dapat terjadi pada anak mulai dari tempat bermain, tempat tidur, mainan, benda-benda disekitar rumah, cuaca, serangga dan hewan lain, serta tumbuhan (Sabrina, 2008).

Kecelakaan menjadi masalah kesehatan umum yang terjadi di negara berkembang dan merupakan penyebab utama terjadinya kematian. Balita merupakan kelompok yang rentan terhadap cedera. Hal ini terjadi karena balita masih dalam perkembangan neuromotorik, kognitif, fisik, sosiopsikologi dan sensori. Kecelakaan di dalam rumah menjadi mayoritas kecelakaan yang terjadi pada balita karena sebagian besar aktivitas anak dilakukan di rumah. Kecelakaan tersebut dapat berupa terjatuh, tenggelam, tersedak, luka bakar, keracunan dan luka sayat (Purwanto, 2013).

\section{METODE PENELITIAN}

Data primer dikumpulkan dengan cara wawancara atau membagikan kuisioner kepada responden untuk mendapatkan data tentang perilaku pencegahan kecelakaan pada balita, dan faktor-faktornya. Data sekunder berupa jumlah balita di wilayah kerja Puskesmas Basuki Rahmad Kota Bengkulu.

\section{HASIL PENELITIAN}

Berdasarkan profil UPTD Pukesmas Basuki Rahmad. Puskesmas ini merupakan puskesmas induk yang berada diwilayah kecamatan Selebar Kota Bengkulu yang terletak dijalan telaga dewa RT XVIII Kelurahan Pagar Dewa. Kecamatan Selebar Kota Bengkulu dengan luas wilayah 27,74 $\mathrm{km}^{2}$. Puskemas Basuki Rahmad mempunyai 4 daerah binaan yaitu Kelurahan Sumur Dewa, Kelurahaan Pagar Dewa, Kelurahan Bumi Ayu, dan Kelurahan Sukarami. Adapun batasbatas wilayah Puskesmas Basuki Rahmad adalah sebelah utara berbatasan dengan Kelurahan Sido Mulyo, sebelah selatan berbatasan dengan Kelurahan Pekan Sabtu, sebelah barat berbatasan dengan Kelurahan Muara Dua, sebelah timur berbatasan dengan Kelurahan Air Sebakul.

Analisis bivariat untuk mengetahui hubungan pendidikan, pengetahuan, sikap, prilaku, ibu terhadap kecelakaan pada balita (Anticipatory Guiduance). di Wilayah Kerja Puskesmas Basuki Rahmat Kota Bengkulu tahun 2015, yang dapat dilihat pada tebel berikut:

Tabel 1 Hubungan pendidikan Ibu tentang prilaku pencegahan kecelakaan pada Balita (Anticipatory Guiduance) di Puskesmas Basuki Rahmat kota Bengkulu 
tahun 2015

\begin{tabular}{|c|c|c|c|c|c|c|c|}
\hline \multirow{2}{*}{$\begin{array}{c}\text { Variabel } \\
\text { Pendidikan }\end{array}$} & \multicolumn{4}{|c|}{$\begin{array}{c}\text { Perilaku Pencegahan } \\
\text { Kecelakaan Pada } \\
\text { Balita }\end{array}$} & \multirow{2}{*}{\multicolumn{2}{|c|}{ Total }} & \multirow[t]{2}{*}{$\begin{array}{c}P \\
\text { Value }\end{array}$} \\
\hline & Kurang & g Baik & Baik & & & & \\
\hline & $\mathrm{f}$ & $\%$ & $\mathrm{f}$ & $\%$ & $\mathrm{f}$ & $\%$ & \multirow{4}{*}{0,028} \\
\hline$\overline{\text { Dasar }}$ & 15 & 65,2 & 9 & 37,5 & 24 & 100 & \\
\hline Menengah & 18 & 34,6 & 34 & 65,4 & 52 & 100 & \\
\hline Tinggi & 4 & 25,0 & 12 & 75,0 & 16 & 100 & \\
\hline Total & 37 & 40,2 & 55 & 59,8 & & 100 & \\
\hline
\end{tabular}

Hasil analisis chi-square menunjukkan bahwa nilai $p=0,028$ lebih kecil dari nilai alpha 0,05 artinya ada hubungan pendidikan ibu dengan prilaku pencegahan kecelakaan pada balita di Wilayah Kerja Puskesmas Basuki Rahmat Kota Bengkulu tahun 2015.

Tabel 2 Hubungan pengetahuan Ibu tentang prilaku pencegahan kecelakaan pada Balita (Anticipatory Guiduance) di Puskesmas Basuki Rahmat kota Bengkulu tahun 2015

\begin{tabular}{|c|c|c|c|c|c|c|c|}
\hline \multirow{3}{*}{$\begin{array}{c}\text { Variabel } \\
\text { Pengetahuan } \\
\end{array}$} & \multicolumn{4}{|c|}{$\begin{array}{c}\text { Perilaku } \\
\text { pencegahan } \\
\text { kecelakaan pada } \\
\text { balita }\end{array}$} & \multirow[t]{2}{*}{ Total } & \multirow{2}{*}{\multicolumn{2}{|c|}{$\begin{array}{c}P \\
\text { Value }\end{array}$}} \\
\hline & \multicolumn{2}{|c|}{$\begin{array}{c}\text { Kurang } \\
\text { Baik }\end{array}$} & \multicolumn{2}{|c|}{ Baik } & & & \\
\hline & $\mathrm{f}$ & $\%$ & $\mathrm{f}$ & $\%$ & $\mathrm{f}$ & $\%$ & \\
\hline Kurang & 16 & 69,6 & 7 & 30,4 & 23 & 100 & 0,004 \\
\hline Cukup & 13 & 30,2 & 30 & 69,8 & 43 & 100 & \\
\hline Baik & 8 & 30,8 & 18 & 69,2 & 26 & 100 & \\
\hline Total & 37 & 40,2 & 55 & $\begin{array}{l}59,8 \\
\end{array}$ & 92 & 100 & \\
\hline
\end{tabular}

Hasil analisis chi-square menunjukkan bahwa nilai $p=0,004$ lebih kecil dari nilai alpha 0,05 artinya ada hubungan pendidikan ibu dengan prilaku pencegahan kecelakaan pada balita di Wilayah Kerja Puskesmas Basuki Rahmat Kota Bengkulu tahun 2015.

Tabel 3 Hubungan sikap Ibu tentang prilaku pencegahan kecelakaan pada Balita (Anticipatory Guiduance) di Puskesmas Basuki Rahmat kota Bengkulu tahun 2015

\begin{tabular}{cccccccc}
\hline Variabel & \multicolumn{3}{c}{$\begin{array}{c}\text { Perilaku pencegahan } \\
\text { kecelakaan pada balita }\end{array}$} & & $\begin{array}{c}\boldsymbol{P} \\
\text { Total } \\
\text { Value }\end{array}$ \\
\cline { 1 - 6 } Sikap & \multicolumn{1}{c}{ Kurang } & Baik & \multicolumn{2}{c}{ Baik } & & \\
\cline { 2 - 6 } & $\mathrm{f}$ & $\%$ & $\mathrm{f}$ & $\%$ & $\mathrm{f}$ & $\%$ & \\
\hline Unfavorabel & 20 & 70,6 & 10 & 29,4 & 23 & 100 & 0,000 \\
Favorable & 13 & 22,4 & 45 & 77,6 & 43 & 100 \\
\hline Total & 37 & 40,2 & 55 & 59,8 & 92 & 100 \\
\hline
\end{tabular}

Hasil analisis chi-square menunjukkan bahwa nilai $p=0,000$ lebih kecil dari nilai alpha 0,05 artinya ada hubungan sikap ibu dengan prilaku pencegahan kecelakaan pada balita di Wilayah Kerja Puskesmas Basuki Rahmat Kota Bengkulu tahun 2015.

\section{PEMBAHASAN}

Hasil analisis chi-square menunjukkan bahwa nilai $p=0,028$ lebih kecil dari nilai alpha 0,05 artinya ada hubungan pendidikan ibu dengan prilaku pencegahan kecelakaan pada balita di Wilayah Kerja Puskesmas Basuki Rahmat Kota Bengkulu tahun 2015. Hasil penelitian ini sesuai dengan yang dikemukakan oleh Suryabrata, (2006), yang mengatakan bahwa pendidikan adalah suatu kegiatan untuk meningkatkan pengetahuan umum seseorang termasuk di dalamnya peningkatan penguasaan teori dan keterampilan memutuskan terhadap persoalan - persoalan yang menyangkut pencapaian tujuan. Hasil analisis chi-square menunjukkan bahwa nilai $p=0,004$ lebih kecil dari nilai alpha 0,05 artinya ada hubungan pengetahuan ibu dengan prilaku pencegahan kecelakaan pada balita di Wilayah Kerja Puskesmas Basuki Rahmat Kota Bengkulu tahun 2015. Hasil penelitian ini sesuai dengan teori yang dikemukakan oleh Notoatmodjo, (2011) mengemukakan bahwa semakin tinggi pengetahuan semakin mudah menerima dan mengembangkan sikap dan perilaku yang akan meningkatkan produktifitas dan kesejahteraan keluarga karena pengetahuan merupakan domain yang sangat penting untuk terbentuknya tindakan seseorang dan perilaku yang didasarkan oleh pengetahuan akan lebih langgeng daripada tidak didasari oleh pengetahuan. Hasil analisis chi-square 
menunjukkan bahwa nilai $p=0,000$ lebih kecil dari nilai alpha 0,05 artinya ada hubungan sikap ibu dengan prilaku pencegahan kecelakaan pada balita di Wilayah Kerja Puskesmas Basuki Rahmat Kota Bengkulu tahun 2015. Hasil penelitian ini sesuai dengan teori yang dikemukakan oleh Notoatmodjo, (2010), yang mengatakan sikap merupakan respons tertutup seseorang terhadap stimulus atau objek tertentu yang sudah melibatkan faktor pendapat emosi yang bersangkutan (senang-tidak senang, setuju-tidak setuju, baik-tidak baik dan sebagainya). Sikap juga merupakan reaksi atau respon yang masih tertutup dari seseorang terhadap suatu stimulus atau objek. Manifestasi sikap itu tidak dapat langsung dilihat, tetapi hanya dapat ditafsirkan terlebih dahulu dari perilaku yang tertutup. Sikap merupakan kesiapan untuk bereaksi terhadap objek di lingkungan tertentu sebagai suatu penghayatan terhadap objek. Dengan kata lain jika seseorang mempunyai sikap yang mendukung terhadap suatu objek akan meningkatkan perilaku yang positif.

\section{KESIMPULAN}

Berdasarkan hasil penelitian tentang faktor-faktor apakah yang berhubungan dengan perilaku pencegahan kecelakaan pada balita (Anticipatory Guidance) di Wilayah Kerja Puskesmas Basuki Rahmad Kota Bengkulu tahun 2015 dapat ditarik kesimpulan sebagai berikut:

1. Ada hubungan pendidikan ibu dengan perilaku pencegahan kecelakaan pada balita di Wilayah Kerja Puskesmas Basuki Rahmad Kota Bengkulu tahun 2015

2. Ada hubungan pengetahuan ibu dengan prilaku pencegahan kecelakaan pada balita di Wilayah Kerja Puskesmas Basuki Rahmat Kota Bengkulu tahun 2015.

3. Ada hubungan sikap ibu dengan prilaku pencegahan kecelakaan pada balita di Wilayah Kerja Puskesmas Basuki Rahmat Kota Bengkulu tahun 2015.

\section{SARAN}

Berdasarkan hasil penelitian yang telah dilakukan maka peneliti memberi saran kepada:

\section{Puskesmas Basuki Rahmad Kota Bengkulu.}

Kepada pihak Puskesmas Basuki Rahmad Kota Bengkulu diharapkan dapat meningkatkan sosialisasi tentang cara pencegahan kecelakaan pada balita kepada masyarakat terutama pada ibu yang mempunyai balita dengan cara melakukan penyuluhan rutin kepada masyarakat misalnya melakukan penyuluhan-penyuluhan rutin di puskesmas, posyandu kelurahan dan tempat lainnya guna menambah pengetahuan, meningkatkan motivasi masyarakat tentang pemberian imunisasi, serta mengikut sertakan keluarga dalam penyampaian informasi tentang pentingnya upaya pencegahan kecelakaan pada balita untuk meningkatkan peran serta keluarga agar aktif dalam mendukung ibu dalam melakukan pengawasan kepada anaknya.

\section{Peneliti selanjutnya}

Kepada peneliti selanjutnya diharapkan mengembangkan penelitian ini dengan melihat faktor-faktor lain yang berhubungan dengan pencegahan kecelakan pada balita seperti motivasi, peran keluarga, sosial ekonomi maupun pekerjaan ibu wilayah penelitian yang lebih luas dan jumlah sampel yang lebih banyak.

\section{DAFTAR PUSTAKA}

Kemenkes RI, 2010, Penuntun Hidup Sehat (Pencegahan Kecelakaan), Kemenkes RI: Jakarta.

Notoatmodjo. 2010. Metodologi Penelitian Kesehatan. PT Rineka Cipta: Jakarta 2011. Ilmu KsehatanMasyarakat. PT Rineka Cipta: Jakarta. .2010. Ilmu Perilaku Kesehatan. Rineka Cipta: Jakarta. 
Purwanto. 2013. Hubungan Tingkat Pengetahuan Ibu Tentang Dampak Kecelakaan Pada Balita Di Rumah Dengan Tindakan Pencegahan Kecelakaan Di Wilayah Posyandu Alamanda 32 Kecamatan Patrang Kabupaten Jember. Skripsi. Program Studi Ilmu Keperawatan Universitas Jember

Sabrina, 2008, Awas, Kecelakaan Di Dalam Rumah, diakses dari http://kabarinews.com pada tanggal 02 desember 2014

Soetjiningsih. 2005. Tumbuh Kembang Anak. EGC: Jakarta 